Brit. F. vener. Dis. (1967), 43, 1.

\title{
FIFTY YEARS SINCE THE CONCEPTION OF AN ORGANIZED VENEREAL DISEASES SERVICE IN GREAT BRITAIN THE ROYAL COMMISSION OF 1916*
}

\author{
BY \\ R. R. WILLCOX \\ St. Mary's Hospital, London, W.2
}

It is now 50 years since the first moves were made to organize an efficient venereal diseases service in Great Britain. The long and detailed Final Report of the Royal Commission on Venereal Diseases, consisting with appendices of some 191 foolscap pages, was published by H.M. Stationery Office (price 1s. 11d.), and its comprehensive studies and wise recommendations have served as an anchor throughout this time, and are likely still to do so for many years to come.

\section{Composition of the Commission}

This was a most distinguished body under the chairmanship of Lord Sydenham of Combe. Its members included Sir Malcolm Morris, who was officially consultant surgeon to the Skin Department at St. Mary's Hospital and whose interest in syphilis had resulted in a paper on salvarsan in the treatment of syphilitic glossitis in 1912 and who had the same year outlined in the Lancet a plea for the establishment of such a Royal Commission. His name is still commemorated to-day in the Malcolm Morris Memorial Lecture which has been given periodically since on a broad subject associated with venereal disease. Other already or soon to be titled participants included Sir John Collie, Director of Medical Service of the Ministry of Pensions and Chief Medical Officer of the Metropolitan Water Board, who was to contribute much as to the incidence of venereal disease amongst so-called "non-venereal" groups; Dr (later Sir) Arthur Newsholme, well known in the field of public health, who had been or was to be president of the Society of Medical Officers of Health and of the Epidemiological Section of the Royal Society of Medicine and who had been Medical Officer of Health in Brighton and Clapham; and $\mathrm{Dr}$ (later Sir) Frederick Mott, consultant physician to Charing Cross and the

\footnotetext{
* Received for publication November 18, 1966.
}

Maudsley Hospitals, an expert on diseases of the brain, especially syphilis of the nervous system. There was also J. Ernest Lane, surgeon at St. Mary's and in charge of the female venereal diseases department of that hospital, who was also attached to the Lock Hospital in nearby Harrow Road; he had written numerous papers on syphilis and gonorrhoea and was to give the Harveian Lecture on the treatment of syphilis in 1917. The lady member of the medical profession was Mary Scharlieb, C.B.E., a gynaecologist with a Harley Street consulting room, on the staffs of the Royal Free Hospital and South London Hospital for Women, who was unusually listed in the Medical Directory for 1920 for her telegraphic address ("Schlarlieb, Wesdo, London").

The Prison Commissioners were represented by Sir Kenelm Digby and the point of view of the prisoners by Canon J. W. Horsley, who had been a prison chaplain for 10 years and was chairman of a large workhouse. The other members, including no less a person than Philip Snowden, were Sir D. Brynor Jones, Sir Almeric Fitzroy, J. Scott Lidgett (a divine), Mrs Louise Creighton (widow of Bishop Creighton), and Mrs E. M. Burgwin. The secretary was E. R. Forber. The commission thus included six members of the medical profession, two churchmen, and two women specially interested in social work.

Amongst those who gave evidence to the Commission were $\mathrm{L}$. W. Harrison, first as major and then as colonel at the No. 9 Stationary Hospital, Le Havre, who was later to take the leading role in the fulfilment of the Commission's recommendations both in an advisory capacity and by his own example in his clinic at St. Thomas' Hospital, and who by the time of his death was generally regarded as "the father of British venereology"; Dr J. J. Pringle, physician-in-charge of the Skin Department of the Middlesex Hospital, who testified on 
marriage and venereal disease-a subject which the Commission considered at some length-and whose name has recently been perpetuated in the shining new venereal diseases department of that hospital; Sir Thomas Barlow, Physician at University College Hospital, and Dr J. H. Sequeira, dermatologist at the London Hospital-who spoke on the same subject; $\mathrm{Mr}$ N. Bishop Harman, ophthalmic surgeon at the West London Hospital, who was concerned with blindness in children; various medical members of the armed forces, and Sir William Osler himself, who expressed the opinion that of the killing diseases, syphilis came third or fourth, and made his often quoted statement that a student who was thoroughly taught syphilis and all of its consequential diseases would acquire a good knowledge of all branches of his profession. In addition, many statements were submitted to the Commission, including one by Sir Donald MacAlister, president of the General Medical Council, and another from the prime minister of New Zealand, W. F. Massey. The report was signed on February 11, 1916.

\section{Atmosphere at the Time}

The commission, when it first met in 1913, could understandably feel that the tools adequate to tackle at least syphilis were at last available. The causative organism ( $T$. pallidum) had been identified by Schaudinn and Hoffmann in 1905, and had already been found in the affected organs of patients in all stages of the disease, the Wassermann reaction had been evolved, and a new and much more effective treatment with arseno-benzol compounds had been introduced by Paul Ehrlich, all of these discoveries having been made in a few immediately previous exciting years and were in the process of being more widely exploited. Tragically, in the following year, Great Britain was to be at war with the homeland of these great medical pioneers.

Moreover, the statistics from the armed forces were showing a steady decline in incidence. The reasons for this were not entirely clear, for it was obviously not solely connected with the new discoveries but was part of a continuing process involving both syphilis and gonorrhoea since 1885 . The reasons given to the commission for this decrease included improved methods of treatment, health education on venereal disease matters to the troops, increased temperance, and increased attractions in barracks (provision of reading and recreation rooms and sports facilities), whereas the Cantonment Act may have contributed to the improvement amongst the army in India. Certainly the alcoholic consumption of the men had markedly declined-from no less than two quarts of beer per head daily in 1901 to $2 \frac{1}{2}$ pints in 1906, with a comparable reduction in the admission rate per 1,000 for alcoholism from $276 \cdot 0$ to $117 \cdot 3$.

The plotted long-term military statistics, as were the declining civilian figures after the second world war, at this time were impressive and surely seemed to indicate that if this could be obtained in the armed forces it could also be achieved for the civilian population. Moreover, there had been pressure in the medical press for the establishment of such a commission.

\section{Nature and Extent of the Problem}

\section{Military Statistics}

The venereal diseases were regarded as comprising syphilis, gonorrhoea, and soft chancre, but it was decided to ignore the last-named as not of public health importance.

The only good available statistics of the extent of the problem were those of the Navy and the Army: these were particularly reliable as affected patients were in the first instance admitted to hospital.

In the Navy in 1912, out of a total sickness loss of $1,101,013$ days, no less than 269,210 were due to venereal disease $(27 \cdot 1$ per cent.). The venereal disease rates for the total strength of 119,540 was 105.9 per 1,000 , which figure had shown some decline since 1905 .

In the Army at home in 1912 (107,582 men) the venereal disease rate was $56 \cdot 5$ per $1,000(16 \cdot 3$ per cent. of all admissions) and some 216,445 days were lost from this cause. The rates had been much higher in earlier times, 275 per 1,000 in 1885 and 292 per 1,000 in 1867, when the Contagious Diseases Acts were in force.

In the Army in India (71,001 men), the venereal disease rate in the same year was 55.5 per 1,000 $(10 \cdot 1$ per cent. of all admissions). In 1895 , considered as reflecting the effects of the South African War, the rate had risen to the astronomical one of 536.9 per 1,000 ( $36 \cdot 8$ per cent. of all admissions). Of the 1912 strength of 37,986 men in the Army in the Colonies, the venereal disease rate was $96 \cdot 6$ per $1,000(22 \cdot 7$ per cent. of all admissions) and this rate too had declined substantially from the $281 \cdot 3$ per 1,000 of 1893 .

If the 1912 venereal disease rates of the British armies of $55 \cdot 5$ to $96 \cdot 6$ per 1,000 did show a striking decline compared with former years, they nevertheless still compared unfavourably with those of some 
other countries. In 1906-7, for example, the comparable rate had been 27.8 in the French and only 18.7 in the German Army, while in the following year that for the German Navy was but 18.5. The figures for the United States Navy, however, were substantially worse-160 4 per 1,000 in 1908-9.

Infectious syphilis accounted for a high proportion of these venereal disease rates. In the Army at home, for example, the total venereal disease rate of $56 \cdot 5$ per 1,000 was compounded of $18 \cdot 7$ for primary and secondary syphilis, $29 \cdot 5$ for gonorrhoea, and 8.3 for soft sore. In the Navy in the same year, the total venereal disease rate of 105.9 per 1,000 comprised $28 \cdot 9$ for primary and secondary syphilis, $57 \cdot 6$ for gonorrhoea, and $19 \cdot 4$ for chancroid.

\section{Civilian Statistics}

When the extent of the problem in the civilian population was considered there was a dearth of adequate factual data. The death rates per million for syphilis, locomotor ataxia, and aneurysm were available from the records of the Registrar General; in 1910 the rates were 150 for England and Wales, 140 for Scotland, and 60 for Ireland, the first two having declined a little since 1901. However, the reliability of such figures was greatly in question and the Commission therefore strongly supported proposals by the Registrar General that medical practitioners should be required to send certificates of the causes of death directly to the registrar instead of handing them to relatives of the deceased, as this practice was considered likely frequently to lead to concealment of the existence of syphilis.

Other official statistics were derived from the notification of stillbirths after 28 weeks under the Notification of Births Act of 1907. In 1912 such stillbirths represented $2 \cdot 46$ to $3 \cdot 40$ per cent. of the registered births, but as the figures were higher in the smaller towns rather than in London these were not particularly helpful.

For gonorrhoea the only official figures related to ophthalmia neonatorum, but this condition had not been made compulsorily notifiable until April, 1914, although it had been notifiable in some districts in the previous year. In these areas the case rate had been 6.5 per 1,000 births $(6.8$ in urban and 1.0 in rural districts). The rates varied widely, e.g. $28 \cdot 1$ in Stoke-on-Trent, 21.4 in Manchester, and 6.1 per 1,000 in the County of London.

Other data were obtained from members of the Metropolitan Police Force, in which up to 1909 all patients with venereal disease had been penalized. In 1911 and 1912, only 96 and 105 members respectively, of a force of approximately 21,000 men had been admitted to hospital with venereal disease, so that the numbers officially known were relatively very small. Figures from the Poor Law institutions were presented by Sir Arthur Downes but these were considered not to represent the prevalence of infection adequately as they had not been originally compiled for this purpose. The commission had therefore largely to make their own channels for the collection of data.

Some figures which had been collected over a 5-month period from the end of 1913 were presented on behalf of the Prison Commissioners by Sir Herbert Smalley. No similar previous data were available. In local prisons, with inmates serving sentences of under 2 years, 1.65 per cent. of 53,064 males and 1.98 per cent. of 14,369 females had symptomatic infection on arrival and approximately one-half were discharged still in an infectious state. A broadly similar situation existed in Scotland and Ireland. Of 1,775 long-term prisoners examined in three convict prisons in England and Wales, 17.04 per cent. showed signs of having had syphilis. Had both these groups been subjected to serum tests, the actual number of infected prisoners would have been found to be considerably greater. Of 941 inmates of Borstal institutions, no less than 153 (16.26 per cent.) were considered to show one or more signs of hereditary syphilis-and there were five cases of acquired syphilis in addition.

A memorandum on the prevalence of general paralysis of the insane was prepared for the commission by the Commissioners in Lunacy. In England and Wales between 1908-12, the rates per 1,000 of the population aged 25-54 years with this condition were calculated to be $7 \cdot 12$ for males and 1.23 for females. In the London County Asylums Dr Mott indicated that in 1911-1912 the proportion of male admissions with general paralysis exceeded 15 per cent.

The Commission tried hard also to get statistics from general hospitals for a 6-month period of the numbers of treated cases of venereal disease. A questionnaire was sent to 285 hospitals in the United Kingdom, but only 67 replies were received. From this "discreditable" performance the Commission were in little doubt that adequate records for statistical purposes were just not kept.

\section{Serological Surveys}

The figures so far referred to, both official and stimulated, were not based on serological findings and were concerned with special groups. Because no data were available as to the prevalence of 
syphilis in the general population, some investigations were undertaken at the request of the commission.

The most important of these was that of Prof. William Bulloch, F.R.S., and Dr Paul Fildes of the Bacteriological Department of The London Hospital, who applied the Wassermann test to 1,002 patients attending the hospital who were specially selected in that they had come for treatment for reasons wholly unconnected with syphilis. Seropositivity rates were found of 10.3 per cent. for males and $5 \cdot 1$ per cent. for females. The statistician consulted, Prof. Karl Pearson, considered the numbers too small for conclusions to be drawn from an age-group breakdown, but it was concluded that, if these figures were a fair sample, at least 8-12 per cent. of adult males in the working population and at least 3-7 per cent. of adult females were suffering from acquired syphilis.

Sir John Collie made further serological studies of men referred for a medical report by large employers, Insurance Companies, etc., which covered 2,176 men seen over a $7 \frac{1}{2}$ month period. Of 1,676 men examined only clinically, 3.58 per cent. had venereal disease, but in 491 apparently healthy men attending for pre-employment examinations who were serologically examined, positive results were obtained in 9.36 per cent.

Other surveys arranged by Dr Mott demonstrated $17 \cdot 1$ per cent. sero-positivity in 545 asylum inmates, $7 \cdot 4$ per cent. in 418 epileptic patients, 8.4 per cent. in 951 insane non-paralytic patients, $8 \cdot 1$ per cent. in 257 feeble-minded children, and 19.9 per cent. in 1,483 Poor Law patients at Shoreditch, Westminster, and Paddington Infirmaries. In tests on pregnant women, or newly-born infants, sero-positivity was 6.6 per cent. in a series of ninety births in St. Pancras, and $19 \cdot 7$ per cent. in 71 Shoreditch cases; the latter included a large number of unmarried women of whom no less than 27.6 per cent. were sero-positive.

With hindsight to-day and experience with more sophisticated tests involving treponemal antigens, it appears likely that these figures were somewhat overstated by the inclusion of false-positive results. Nevertheless they were widely interpreted at the time as indicating that 10 per cent. of British manhood had syphilis, the shock of which did much to carry through the Commission's recommendations.

\section{Recommendations concerning Statistics}

No wonder that a number of the Commission's recommendations concerned the provision of better civilian statistics. Of the 35 items in the summary of recommendations, the first five were concerned with this aspect.

The most important was that all institutions undertaking with exchequer grants the diagnosis and treatment of venereal diseases should keep and make available adequate aggregate statistics, and we now have the excellent figures published each year by the Ministry of Health. Other recommendations included the plea that registration of the cause of death should be confidential, that stillbirths earlier than the 28th week of pregnancy should be notified, that Local Government Boards should devise a uniform system of records of sickness in hospitals and Poor Law establishments, and that statistics should be kept of patients provided with arsenobenzol compounds at public expense.

\section{Effects of Venereal Diseases}

\section{Syphilis}

The Commission considered at some length the symptomatology, effects, and diagnosis and treatment of both syphilis and gonorrhoea, and the reader will still appreciate the succinct clinical descriptions supported by photomicrographs of $T$. pallidum in serous exudates and in tissue smears and epidemiological charts of the military statistics. The clinical descriptions of congenital syphilis are especially good and all writers of venereal disease textbooks to-day would benefit from reading these pages.

For data on the course of the disease in these preBruusgaard and pre-Gjestland days, the Commission drew on a paper by two Viennese doctors, Mattauschek and Pilz, concerning the cause of death of 4,134 officers who contracted syphilis between 1880 and 1900. Of these 198 developed dementia paralytica, 113 locomotor ataxia, and 132 cerebrospinal syphilis, and seventeen died of aortic aneurysm. If syphilis maligna praecox was also included, it was considered that 12 per cent. became seriously ill or died from the disease. Also the records of the Gotha Life Insurance Company showed that the mortality rate amongst syphilitics aged 36 to 50 years was well nigh double the average, and other insurance records showed mortality rates at all ages to be about 30 per cent. above the average.

Of particular interest to the present-day reader is the statement contained in an appendix of the exmanaging director of a family glass works at Castleford in Yorkshire, which documents the historical hazard of so-called innocent syphilis amongst glass blowers. It refers to four outbreaks of syphilis 
amongst the workers during a 15-year periodincluding a number of cases of chancre of the lip. Boys aged 15 to 18 years were particularly at risk. In the process of blowing glass bottles, the blowpipe with the lump of molten glass at the end of it was passed from hand to hand and mouth to mouth. One of the doctors who examined the men recommended that each should be provided if possible with a separate mouthpiece to fit his pipe. However, the management indicated that there was no practicable way to get over this difficulty except by machine processes which dispensed with hand labour to a great extent, particularly with the recent Owen machine which obviated hand labour entirely. But it was observed that "The workmen are much opposed to machinery (perhaps naturally)".

\section{Gonorrhoea}

Although excellent photomicrographs show the presence of gonococci in pus from cases of gonococcal ophthalmia and vulvovaginitis, there is much less information in the Report concerning gonorrhoea which, although it was well known to have serious and far reaching consequences, was generally regarded by the public as a trifling ailment. It accounted, the Commission considered, for 50 per cent. of sterility in women and might lead (with streptococci and staphylococci) to puerperal septicaemia and death. Evidence was given by Mr Frank Kidd that, at The London Hospital, no less than 200 infants with gonococcal ophthalmia had been treated in the ophthalmic ward in the previous 6 years, 48 having been discharged with the eyes permanently damaged, five of whom died. In Kidd's evidence it was stated that the gonococcus had been demonstrated in 17.4 per cent. of cases of salpingitis, but the actual incidence was considered to be much higher, as in about 60 per cent. the cultures had been sterile.

Epididymitis occurred in about 15 per cent. of male cases. In 10 years no less than 894 cases of stricture had been admitted to The London Hospital and 876 cases were admitted to two other large general hospitals. As only severe cases necessitated admission, the actual prevalence was much greater. The operative mortality on stricture at that time was 6 per cent. but more important still were the back-pressure effects whereby the kidneys were "pressed out of existence".

It is evident that much of what is regarded to-day as Reiter's syndrome was included under the heading of complications of gonorrhoea. Trichomoniasis was also confused, insofar as vaginitis in the adult female was then considered to be part of the symptom-complex caused by the gonococcus.

\section{Diagnosis of the Venereal Diseases}

The attention of the commision was concentrated almost entirely on the diagnosis of syphilis. The method of dark-field diagnosis of the disease was demonstrated to its members by "a most experienced witness", the then unpromoted Major Harrison at the Royal Army Hospital, Rochester Row, in London. He anticipated the "mail in" diagnosis at present being elaborated in the U.S.A. using the direct F.T.A. test, by indicating that the general practitioner could, if he wished, send in samples of exudate to a central laboratory for examination.

The Luetin test, a skin test using Noguchi's (at that time still credited) cultured organism-which is illustrated-was also described, although it was seldom employed. The reaction, read after 48 hours, was found to be positive in late, latent, and congenital cases, but not often in the early infection. The principles of the Bordet-Wassermann reaction (not as a rule positive "till at least 15 days after the sore has appeared") were outlined in detail with histograms showing interlocking complement, antigen, and a central amboceptor. The cerebrospinal fluid findings in neurosyphilis were all described in an excellent appendix by Dr F. W. Mott.

A subcommittee of the Section of Pathology of the Royal Society of Medicine had held five meetings particularly to report on the various techniques used in the Wassermann reaction. Amongst other methods it considered those of Hecht and Fleming which were substantially identical, except that Fleming's employed very small quantities of ingredients and was suitable for finger-prick blood. It is of interest that while Hecht's name has persisted in this respect Fleming's did not, and it would seem to be but by chance that he was not to achieve world-wide acknowledgement in syphilis serology years before his discoveries of lysozyme and penicillin. Fleming had considerable interest in the subject in those days and had been one of the first to treat cases of syphilis with salvarsan in this country (Maurois, 1959).

Although the diagnostic techniques were being used in the larger hospitals, the over-all facilities were still inadequate for what the Commission had in mind and, as would be expected, it was recommended that such facilities be widely extended. It was proposed that the organization should be entrusted to the larger local authorities, but nevertheless making the fullest use of laboratory services at 
universities and hospitals. As in other costing arrangements, three-quarters of the cost was to be provided from Exchequer funds and one-quarter from local rates.

\section{Treatment of the Venereal Diseases Syphilis}

Several lengthy memoranda on the results of the treatment of syphilis in the armed forces were presented. The situation was not unlike that which obtained after the introduction of penicillin 30 or so years later, when there was an unwillingness to accept entirely the new therapy to the complete abandonment of the older tried methods. While salvarsan and its derivatives clearly greatly improved on the results of the older mercury treatment, combined treatments were still the rule albeit in an intensified form. The combined method which had been introduced by Neisser consisted in the combination of periodic intravenous injections of salvarsan or its derivatives followed by either five intramuscular injections of an insoluble mercurial preparation (calomel cream or grey oil) or a course of thirty inunctions.

Mercury Alone Army data were provided showing the results of treatment with mercury alone either by injection or inunction. Of 378 cases the average in-patient stay on first admission was 42 days and there were 315 patients ( 33.0 per cent.) with clinical relapses-which occurred three or more times in 49 patients. In the Navy mercury was given by mouth-and the treatment might last for from 1 to 4 years-while at the Haslar Hospital injections of a metallic mercury cream were being used. The clinical relapse rate was assessed at around 50 per cent., and of 384 cases investigated serologically, sero-negativity was reached in only $28 \cdot 5$ per cent.

Salvarsan combined with Mercury Once combined treatment with salvarsan had been introduced into the Army, the average number of days in hospital on first admission (for 152 cases reported) was reduced to $23 \cdot 2$, and only six of these patients (3.9 per cent.) relapsed clinically, none more than once. However, taking serological relapses into account also, the figures were less impressive, the failure rates being 11.4 per cent. for primary and 33.8 per cent. for secondary syphilis; this further emphasized the necessity for prompt early treatment, which requirement remains even to-day with penicillin, if reversal of the TPI reaction is to be achieved.
In the Navy some 4,203 cases in which salvarsan or neosalvarsan had been used were reported in an almost modern statistical presentation. The great majority had received only two or three injections, but even so there were only $3 \cdot 2$ per cent. of clinical relapses. After only two injections sero-negativity was obtained in 93.4 per cent. of cases of seronegative primary syphilis, 69 per cent. of seropositive primary syphilis, and in 54.7 per cent. of secondary syphilis in the first year, but in only 33.4 per cent. of late cases, which further emphasized the need for early treatment. Because of such findings the courses of treatment were later to be more prolonged.

The Navy series included three deaths due to therapy but one was complicated by diphtheria. Arsenical encephalopathy, which again made an impact during the second world war, was noted early, for there were three cases of epileptiform convulsions occurring suddenly after the second injection in which consciousness was not restored for 12 hours or more. Venesection apparently gave "extremely beneficial" results in these cases.

A difficulty concerning treatment arose while the commission was sitting, for the original arsenobenzol compound salvarsan, and the newer less toxic and more practicable neosalvarsan, were both manufactured in Germany and, on the outbreak of war, the patents and trade-marks were suspended by the Board of Trade. However, similar compounds were soon being made by the Allies, kharsivan and neokharsivan in Britain and arseno-benzol-Billon, novarseno-benzol-Billon, (and a now forgotten preparation containing phosphorus-Galyl) in France, all of which were soon being reported on as being as satisfactory as the original German products.

\section{Gonorrhoea}

Scant data were presented of the results of the treatment of gonorrhoea, mainly in a statement of evidence by $\mathrm{Mr}$ Frank Kidd, F.R.C.S., of The London Hospital, who bemoaned the fact that until recently little attention had been paid to the treatment of urethritis in England. Although genitourinary clinics had long been established in America, France, and Germany, the only such clinics in London were one at Guy's Hospital and one which Kidd himself had recently started at The London Hospital.

The old-fashioned treatment of gonorrhoea was the "do nothing" method with sandalwood oil, but Kidd presented much better results with urethral 
irrigations, claiming that all but one of 100 patients were cured, and that of 39 seen in the early stages all were cured within 6 weeks. However, if the disease had already spread to the deeper partswhich it had in 58 per cent. of his small series of 180 cases-then it was unusual for the patients to be cured in less than 4 to 5 months. No good results had been obtained with vaccines. A major difficulty lay in getting patients to come for treatment as "young men have until lately treated the disease as something laughable".

Kidd strongly advanced proposals for the establishment of genito-urinary clinics at hospitals which could treat both males and females, but he believed that syphilis should still remain in the hands of the dermatologist.

\section{Facilities for Treatment}

The facilities for treating venereal diseases were reviewed by the Commission by means of visits by its members or by doctors designated for the purpose-including a Dr Johnstone who died before the report was signed. It was firmly concluded that facilities were "extremely deficient". The special venereal diseases hospitals in London, Glasgow, and Dublin did excellent work, but evidence showed that the accommodation provided for the hospital treatment of patients suffering from the early stages of the disease were "altogether insufficient" and "wholly inadequate". Although the more progressive hospitals had recently made special provision, the honorary medical staff testified that patients with infectious venereal disease were not encouraged to attend general hospitals (in some it was contrary to local statute) although the same institutions would admit patients suffering from the late manifestations. It was pointed out that the efficient treatment of early infections would later set free many beds then occupied by advanced cases.

The Commission's recommendations in this field were broad and sweeping and that so many have survived virtually untouched for over half a century is proof of their long-term wisdom.

It was affirmed that the best modern treatment should be provided for the whole community in such a way that none should be deterred from seeking it. Although it was recognized that the general practitioner was the first line of defence, some of whom were to be given free arseno-benzol preparations for the purpose, a much more comprehensive scheme was required; although this should be organized by the local authorities, institutional treatment should be given at the general hospitals, the governors of which should be approached regarding this in the first instance. (Dr Johnstone had already made some preliminary soundings of the likely attitude of certain hospitals.) Treatment should be free and confidential and not restricted to patients from any given area, and special arrangements, such as evening clinics, should be made to provide out-patient treatment at hours convenient to the working classes.

All doctors treating syphilis and gonorrhoea should be obliged to hand out to their patients cards of instruction and warning which should be provided at the public expense. This practice was followed throughout the arsenic and bismuth era, but since the introduction of penicillin it has largely lapsed; it might now with advantage be revived in a modified form.

The means for the diagnosis and treatment of venereal diseases by modern methods should also be made available in prisons. When a local examination of a woman prisoner was necessary it should be made by a woman doctor. Arrangements should be made through the Discharged Prisoners' Aid Association or similar bodies for someone to keep in touch to ensure continuance of therapy on discharge.

\section{Notification of Venereal Disease}

The commission was aware that patients were deterred from seeking treatment because of shame exaggerated by the attitude of society and because of the penalties which might be exacted. For example, under the National (Health) Insurance Act each insured person was entitled to sickness and medical benefit when ill and, if suffering from venereal disease, to receive medical attendance and treatment. However, under the rules of most benevolent societies, insured persons suffering from venereal disease were suspended from sickness and disablement benefit unless the disease was not caused by their own misconduct, and some (but not all) societies strictly enforced this rule. The Commission regarded the application of such a rule as likely to deter patients from attending for treatment and therefore as contrary to the public health and economy.

The medical profession itself was also involved; it was noted that certain doctors refused to treat venereal disease but gave a moral discourse instead. It was reported that one doctor had actually written to a patient as follows: "You have had the disease one year and I hope it may plague you many more to punish you for your sins and I would not think of treating you". 
For these reasons and because of misleading advertisements many patients consulted chemists or unqualified persons. A representative of the National Association of Medical Herbalists was called and "effectively disposed of claims of herbalists to be regarded as competent to treat venereal disease". The Commission therefore endorsed the recommendations of the Select Committee on Patent Medicines which sought to prohibit all advertisements of remedies for venereal diseases and hoped that, when legal difficulties could be overcome, the treatment of venereal diseases by unqualified persons would be made a penal offence.

The deterrent factor and the possibility of driving persons to seek advice from quacks influenced the Commission's deliberations on notification, the advantages and disadvantages of which were considered at some length. The practices in other countries were examined, as was a long statement of evidence relating to Denmark by Dr Svend Lomholt. The Commission finally decided against notification for the reasons stated and because many practitioners would be reluctant to notify. However they were not as firm on this point as has often been asserted, and they did make the point that when experience had been gained of improved facilities this matter should be further examined. In the meantime some form of anonymous notification for purely statistical purposes was suggested for consideration, although from Dr Lomholt's evidence it was doubted if accurate statistics would be forthcoming even by this method.

Objections similar to those against notification existed against the compulsory detention of infectious patients in hospital, which was not believed to be practicable although considered to be justifiable in certain cases. Poor Law patients suffering from venereal diseases were cited as one such example (this to-day would be regarded as social discrimination); it was, however, recommended that the wards set apart for the treatment of venereal diseases in Poor Law institutions should be suitable and cheerful and that the best modern treatment should be available. Likewise, patients in the armed forces whose service had not expired should be detained until they were pronounced non-infectious, and if they were discharged arrangements should be made for them to attend the local authority hospital or clinic.

\section{Health Education}

Among the many recommendations concerning health education it was suggested that medical students and practitioners should have access to the treatment of venereal diseases in any institution dealing with these diseases; instruction in venereal (and skin) diseases should be given to every medical student, if necessary by means of compulsory attendance, and questions relating to syphilis and gonorrhoea should be systematically set in medical and surgical examinations; Sir Donald MacAlister stated, however, that the latter was already being done.

For the public as a whole more careful instructions should be given in regard to "moral conduct as bearing on sexual relations" throughout all grades of education. Such instruction should be based on moral and spiritual considerations and not solely on the physical consequences of immoral conduct. Detailed class instruction on sexual matters should not be undertaken in elementary schools, but head teachers should (as many did) give moral instruction and warnings against probable temptations in private interviews to school-leavers and before this to those in special need of guidance. More detailed instruction should, however, be given in evening continuation schools, factories, and workshops, and to entrants to the Army and Navy. Students in training colleges should be carefully prepared to enable them to deal with these subjects.

The Commission finally recommended that the (now defunct or absorbed) National Council for Combating Venereal Diseases should be recognized by the government as an authoritative body for the purpose of spreading knowledge and giving advice on venereal diseases in their various aspects, and that only literature approved by this body should be used by the educational authorities. This split between the administrative authority and those providing propaganda material still largely persists.

\section{Venereal Disease and Marriage}

Much time was spent by the Commission in considering questions related to venereal disease and marriage and many witnesses were consulted. It was not considered practicable, however, "at present" to organize a satisfactory method of certification of fitness for marriage, but it was proposed that a bona fide communication of a doctor to a parent, guardian, or other person directly interested in the welfare of a woman or man with the object of preventing or delaying marriage with a person suffering from infectious venereal disease should be a privileged communication and that statutory recognition should be given to the fact that infectious venereal disease constituted an incapacity for marriage (with a clause to exclude a decree of nullity from making children illegitimate). 


\section{After the Report}

The Commission issued its Report "at a time when all public activities were preoccupied in fulfilling the manifold needs of war". Their fears, however, that their recommendations might not receive the immediate attention their national importance demanded were to prove groundless. Even with more shocking news from the battlefields of Europe, the public were shaken by the Report and action was prompt. In the same year the most important recommendations were embodied in the Public Health (Venereal Diseases) Regulations of 1916, in which the Councils of Counties and County Boroughs were instructed to organize the free and confidential treatment of persons suspected of suffering from venereal disease at hours convenient to patients-a duty now assumed by the Regional Hospital Boards. The following year the Venereal Diseases Act was passed, which prohibited, under penalty, unqualified persons from treating these diseases, and forbade advertisements by persons other than local authorities concerning their treatment or prevention (Roberts and Shaw, 1966).

The effects of the Commission's recommendations are still clearly apparent to-day: many still have the freshness and aptness they had 50 years ago, for indeed many of the problems remain.

The establishment of venereal disease clinics initiated by the local authorities ensured in the long run that the treatment of both syphilis and gonorrhoea in males and females was conducted under the same roof, and this, in spite of the opinion of $\mathrm{Mr}$ Kidd, prevented the division of the specialty into dermatologists treating syphilis and genitourinary surgeons treating gonorrhoea, as still occurs in many countries, and led to the emergence of the "pure" venereologist which is almost unique to Great Britain. This arrangement has served well, although it is possible that in the past research in the specialty has been impeded by a lack, or slowness, of the cross-fertilization of ideas which might have occurred from more direct contact with other fields of study. Certainly most advances have come from the application or variation of techniques first used outside the subject rather than from venereology itself, but venereology is not alone in this. What was ensured was that the subject was practised by those interested in it and not as a side-line by persons whose main activities lay elsewhere. The professional forum, the Medical Society for the Study of Venereal Diseases, was founded in 1922 (Harrison, 1961) and in the current year has an alltime record number of members.
The main rationale which motivated the Commission's recommendations was the acceptance of the proposition that medical evidence had established that by early efficient treatment the venereal diseases "could be brought under control and reduced within narrow limits". How right were they in thinking thus? For syphilis (with some recent reservations) they could be said to have been justified. In 1925, the first year for which the new statistics were available, there were 11,782 cases of syphilis in males and 7,385 in females attending the clinics of England and Wales (Ministry of Health, 1948). In 1964 these totals had been reduced to 2,507 and 1,268 respectively in a much larger population (Ministry of Health, 1965). But for gonorrhoea, the male and female totals of new cases in 1925 were 24,398 and 6,120 respectively, whereas in 1964 they were appreciably higher-29,050 and 8,615 . And this in spite of the introduction of new methods of therapy far more rapid, powerful, and efficient in action than the salvarsan derivatives and urethral "injections" considered by the Commission; moreover, there is to-day a very adequate service widely used by the population for early treatment.

Thus the provision of early, adequate, free, and confidential treatment has not so far been sufficient to confine these diseases to the hoped-for narrow limits. Currently efforts are being intensified to ensure even earlier treatment being given, by using contact-tracing measures aimed at identifying infected and potentially infected patients before they have had time to infect others. If these intensified measures are more successful, the Commission's main thesis may still be shown to have been correct.

\section{REFERENCES}

Harrison, L. W. (1961). Brit. F. vener. Dis., 37, 2.

Maurois, A. (1959). "The Life of Sir Alexander Fleming", trans. G. Hopkins, Jonathan Cape, London.

“The Medical Directory" (1920). 76th Annual Issue. Churchill, London.

Ministry of Health (1948). "Report of the Chief Medical Officer for 1946, Appendix C", included in the Ministry Report for 1947. H.M.S.O., London.

(1965). "Report of the Chief Medical Officer for 1965, Appendix C". H.M.S.O., London.

Roberts, L., and Shaw, C. H. (1966). "A Synopsis of Hygiene (Jameson and Parkinson)", 12th ed. Churchill, London.

Royal Commission on Venereal Diseases (1916). "Final Report of The Commissioners". H.M.S.O., London. 